\title{
Molecular mechanisms and treatment strategies for Dupuytren's disease
}

This article was published in the following Dove Press journal:

Therapeutics and Clinical Risk Management

27 August 2010

Number of times this article has been viewed

\author{
David B O'Gorman 1,2,3,4 \\ Linda $\mathrm{Vi}^{1,2,5}$ \\ Bing Siang Gan'1,2,3,5,6 \\ 'Cell and Molecular Biology \\ Laboratory, ${ }^{2}$ The Hand and Upper \\ Limb Centre, St. Joseph's Health Care \\ London, Schulich School of Medicine \\ and Dentistry, ${ }^{3}$ Departments of \\ Surgery, ${ }^{4}$ Biochemistry, ${ }^{5}$ Physiology \\ and Pharmacology, ${ }^{6}$ Medical \\ Biophysics, The University of Western \\ Ontario, London, OT, Canada
}

\begin{abstract}
Dupuytren's disease (DD) is a common disease of the hand and is characterized by thickening of the palmar fascia and formation of tight collagenous disease cords. At present, the disease is incurable and the molecular pathophysiology of DD is unknown. Surgery remains the most commonly used treatment for $\mathrm{DD}$, but this requires extensive postoperative therapy and is associated with high rates of recurrence. Over the past decades, more indepth exploration of the molecular basis of DD has raised the hopes of developing new treatment modalities. This paper reviews the clinical presentation and molecular pathophysiology of this disease, as well as current and emerging treatment. It also explores the implications of new findings in the laboratory for future treatment.
\end{abstract}

Keywords: Dupuytren's contracture, Dupuytren's disease, fibrosis

\section{Introduction}

Dupuytren's disease (DD), also known as Dupuytren's contracture, is a common pathologic condition of the hand. The hallmark of the disease is the formation of occasionally painful nodules in the palm of the hand and of tendon-like cords that lead to flexion deformities of the affected fingers. This pathology can lead to pain upon gripping, but most patients seek medical attention when contractures result in limitations in dexterity. Patients complain about not being able to put their gloves on or that they cannot grasp objects well. Often there are social concerns, such as embarrassment when shaking hands. ${ }^{1}$ Treatment is mostly offered to patients who desire correction of flexion deformities or to those who are bothered by the painful nodules. However, in the absence of a full understanding of the molecular pathology, treatment is currently aimed at eliminating the contracted pathologic disease tissue, without correcting the underlying pathophysiology. Because of this, recurrences are common and current work is aimed at a deeper understanding of the disease process. This review summarizes the clinical presentation of the disease, reviews current and emerging treatment, and touches on new data regarding the molecular pathophysiology of DD. It also explores the implications of these advancements for future work.

\section{Clinical presentation and anatomy}

DD often occurs bilaterally, but typically affects one hand more severely than the other. The earliest signs of DD involve changes in the skin, such as the presence of pits in the skin of the palm or changes to the skin on the dorsum of the hand with the presence of knuckle pads or Garrod nodes. ${ }^{2,3}$ 
The ring and small fingers are most often involved, although the other fingers and thumb may also be affected. ${ }^{3}$ The disease is thought to progress from a palmar nodule into a longitudinal cord. These cords seem to follow normal palmar fascial structures which in their healthy states are designated as "bands". As the cord matures, it contracts and becomes more fibrotic, taking on a more distinct tendon-like appearance and resulting in flexion contractures of the digits. ${ }^{4}$

In the palm, the most common cord is the precentral cord, which arises from the precentral band of the palmar fascia and typically results in a flexion deformity of the metacarpophalangeal (MCP) joint. Other cords in the palm include the vertical and natatory cords (arising respectively from the vertical bands of Legueu and Juvara and the natatory ligaments), although these are less common than the precentral cord. ${ }^{5}$

In the fingers, the most common cords are the central, lateral, and spiral cord. ${ }^{4}$ The central cord is an extension of the precentral cord that forms in the midline of the fingers and attaches to the flexor tendon sheath. This cord can cause deformities in the MCP joint and proximal interphalangeal (PIP) joint. The lateral cord is a continuation of the bifurcated precentral cord and is considered the pathologic state of the lateral digital sheath. Unlike the central cord, it attaches to the skin or to the tendon sheath near Grayson's ligament. This cord usually results in deformities of the PIP joint, but can also affect the DIP joint. The spiral cord is also an extension of the precentral cord that starts off deep to the neurovascular bundle and distal to the MCP joint. In the digit, the cord advances lateral to the neurovascular bundle to involve the lateral digital sheath and then superficial to the neurovascular bundle to involve Grayson's ligament. In doing so, the cord wraps itself around the neurovascular bundle, which causes the superficial, proximal, and central displacement of the neurovascular bundle when finger contractures are produced. This displacement puts the neurovascular bundle at risk of damage during surgery. ${ }^{3}$

\section{Prevalence and risk factors}

DD is considered an inherited dominant condition with variable penetrance, affecting males more often than females. ${ }^{6}$ Typically, disease onset is in the fourth or fifth decade of life in males, while the disease tends to develop later in life for females. ${ }^{6,7}$ Although primary DD is more prevalent in males, the probability of recurrence is approximately equal between the sexes after surgery. ${ }^{6} \mathrm{DD}$ has been traced to a population of Germanic and Celtic tribes who migrated across Northern Europe to Scandinavia and to the British Isles. From there, the disease was brought by emigrants to the New World, including Australia and North America. DD is less common in other parts of the world, such as Southern Europe, South America, and Asia, ${ }^{8}$ although in certain populations within this area, specifically Japan and Taiwan, higher prevalence rates have been reported. ${ }^{9}$ In Iceland, the prevalence of DD can be as high as $40 \%$ in males over 70 years. ${ }^{10}$

In 1963, Hueston first described a "Dupuytren's diathesis", a term which describes factors that would strongly predict disease severity and disease recurrence after treatment. ${ }^{11}$ Patients of Northern European descent, those who present at a younger age of onset, and those who have a positive family history of DD have an increased probability of developing the condition, as well as having a more aggressive disease progression. Similarly, patients who have bilateral hand involvement and ectopic lesions (such as knuckle pads, plantar fibromatosis [Lederhosen disease], or penile fibromatosis [Peyronie's disease]) are more likely to have aggressive disease progression and an increased risk of recurrence. The severity of a patient's disease presentation continues to be an important factor in the management of this disease, and recently the statistical risk for disease recurrence based on these diathesis factors has been calculated. ${ }^{12}$

In addition to genetic factors, a number of comorbidities and socioenvironmental factors play a role in this condition. Studies have suggested that DD clusters in patients with certain underlying health conditions, such as diabetes mellitus ${ }^{13,14}$ and epilepsy. ${ }^{15}$ Lifestyle risk factors that have been associated with DD include smoking and high alcohol consumption. ${ }^{16-18}$ Other factors, such as manual labor, ${ }^{19}$ hand or wrist trauma, ${ }^{20}$ and a history of repetitive hand vibrations ${ }^{21}$ have also been associated with the disease. The contributions of these factors remain controversial, however, and other studies have been unable to identify any correlation. ${ }^{22}$

\section{Treatment}

While the current research focus is on the identification of potential molecular therapies for DD management, the most widely practiced intervention is still surgical resection of the disease cords. ${ }^{23,24}$ Surgical treatment is based on the simple premise that the disease cords prevent the fingers from extending and that excision of the diseased tissue leads to "freeing-up" of the joints and return of range of motion. Review of the surgical results, however, often shows incomplete return of range of motion and considerable rates of recurrence. Nonetheless, because surgery still forms the mainstay of treatment, we will include surgical treatment of DD in this review. 


\section{Surgery for Dupuytren's disease}

Surgical intervention is typically considered when the contracture significantly affects hand function. This is usually where the MCP and/or PIP flexion contracture exceeds $30^{\circ}$, and many surgeons use a simple assessment such as the "table-top test" to determine appropriateness for surgery. This "table-top test" dictates that once a hand can no longer be placed flat on the table, consideration should be given to surgical release. ${ }^{25}$

There are a number of surgical variations available to address finger contractures in DD. Multiple options to expose the fascia have been described, including longitudinal midline incisions closed with Z-plasties, Bruner-type zigzag incisions, and multiple transverse incisions. ${ }^{26}$ Most operations for the correction of DD contractures involve some form of palmar fasciectomy, and fasciectomy can be divided into local, regional, and radical fasciectomy. Of the three, local fasciectomy is the least invasive, and involves resection of segments of the disease cord, thereby releasing finger contracture. Because residual disease tissue remains in the hand following the local fasciectomy procedure, the chance of recurrence is high. ${ }^{3}$ A more extensive approach is regional or partial fasciectomy, a technique involving the removal of as much of the affected fascia as possible. ${ }^{27}$ Radical or total fasciectomy is a more invasive procedure, involving the excision of the palmar and digital fascia. This technique is associated with an increased risk of surgical complications and does not have lower recurrence rates when compared with partial fasciectomy. ${ }^{28}$

For less advanced disease involving only palmar cords, the use of fasciotomy has been advocated. Fasciotomy is a technique used to release contractures by dividing the disease cord without the excision of the diseased tissue. ${ }^{29}$ As the diseased tissue is not removed, the risk of disease recurrence is relatively high. ${ }^{30}$ The closed procedure, often referred to as needle fasciotomy or needle aponeurotomy, involves the placement of a needle adjacent to the cord, and "slicing" or "piercing" of the disease cord with the sharp beveled edge of the needle to release the contracture. ${ }^{31,32}$ While this procedure is minimally invasive in nature, most surgeons still believe that it should be used with caution because it puts the flexor tendons and nerves at risk of being severed during surgery. ${ }^{32}$ It is currently believed to have a role only in the management of mild to moderate MCP contractures. An alternative approach to the closed fasciotomy is the open fasciotomy procedure. This approach involves creating an incision in the palm of the hand, allowing visualization of the disease cord. The cord can then be severed, thereby releasing the contracture. This procedure is less invasive than closed fasciotomy, but has the advantage of reducing the risk of damage to the nerves in the hand because it allows for direct visualization of the disease cord.

For management of aggressive or recurrent disease, dermofasciectomy has been recommended. This extensive technique involves excision of the diseased fascia en bloc with the overlying skin, and subsequent use of skin grafts to close the skin. ${ }^{33,34}$ Compared with fasciectomy alone, dermofasciectomy offers a lower chance of disease recurrence. Because of this, despite longer postoperative rehabilitation, this technique is sometimes recommended for younger patients or for those with Dupuytren's diathesis and a history of aggressive disease recurrence.

To improve long-term results, splinting is prescribed as a postoperative physical therapeutic modality. ${ }^{35}$ While the effectiveness of splinting without surgery is dubious, most surgeons would still advocate it as an adjunct to surgery to maximize finger extension and function. ${ }^{3,36}$ After the acute wound healing stage has passed, most surgeons would also continue night splinting to maintain extension in the remodeling phase of wound healing.

Recurrence rates following surgery remain high and, recurrence rates increase with longer follow-up periods. ${ }^{3}$ Complications of surgery include digital nerve injury, skin flap loss, wound healing problems, infection, hematoma, and postoperative stiffness. Occasionally patients develop a regional complex pain syndrome or exhibit prolonged postoperative inflammation requiring prolonged hand therapy. ${ }^{37} \mathrm{In}$ the end, some patients with a history of multiple recurrences or surgery-associated complications opt for amputation of the affected finger(s) rather than undergo further surgery.

\section{Biologic treatment approaches}

Because of the high rates of disease recurrence and inherent risks of surgical intervention, a shift in focus of recent research in DD has been towards identifying potential molecular targets for nonsurgical alternative therapies.

The most straightforward nonsurgical treatment of DD has been to accomplish the same as surgical removal of the disease cords but by enzymatic digestion of the cord. This approach has been tried for a number of decades with variable success. In 1971, Hueston reported that enzymatic fasciotomy can achieve similar outcomes to surgical fasciotomy, and suggested that it may be an appropriate alternative for selected patients. ${ }^{38}$ Enzymatic fasciotomy is the injection of a cocktail of proteolytic and anti-inflammatory enzymes, specifically trypsin, hyaluronidase, and lidocaine, to disrupt 
the collagenous nature of the disease environment. ${ }^{38}$ This injection is followed by physical manipulation to straighten the digits, breaking the disease cord and releasing the contracture. Because the disease cords are primarily composed of Type I and Type III collagen, ${ }^{14,39,40}$ more recently, investigators have been starting to use a mixture of clostridiumderived collagenases, Clostridium hystolyticum Type I and Type II, which specifically target the $\mathrm{NH}_{3}$ and $\mathrm{COOH}$ terminals and internal peptide residues, respectively, in collagen fibers. These enzymes belong to the matrixin subgroup of the metalloproteinases, requiring $\mathrm{Zn}^{2+}$ and $\mathrm{Ca}^{2+}$ for activity. A number of studies have now provided data that collagenase injection into disease cords improves finger contractures and improves joint mobility in advanced disease..$^{14,41-44}$ Marketed as Xiaflex ${ }^{\circledR}$ (Auxilium Pharmaceuticals, Inc.), these injections can be considered as a nonoperative alternative to surgery. However, like surgery, this approach targets a result of the disease process, ie, excess collagen deposition, rather than the cause of the disease, which is thought to be hyperproliferative, contractile, and collagen-producing disease cells within the palmar fascia. Finally, because collagenase does not act specifically on the disease cord structure, the long-term safety of injecting this enzyme into other structures of the hand that also contain collagen, such as tendons, ligaments, and neurovascular bundles, should also be considered. The current evidence suggests that collagenase C. hystolyticum specifically targets fibrillar collagens such as Type I and Type III (but not Type IV) collagen, the primary collagen constituent of blood vessels. The long-term rate of recurrence, as well as safety of collagenase treatment of $\mathrm{DD}$, is currently being evaluated in several Phase III trials.

The use of corticosteroid injections has been advocated as a treatment for early disease or for painful nodules. Intralesional injection of a corticosteroid directly into palmar nodules can result in softening and reduction of pain. ${ }^{45}$ This correlates with molecular studies which show that steroids can function as an antifibrotic agent, reducing cell proliferation, while inducing apoptosis or programmed cell death..$^{46,47}$ The potential side effects of steroid use are skin depigmentation and dermal atrophy from collagen degradation..$^{48,49}$ Rarely, flexor tendon ruptures have been described.

Another biologic agent to address the observed cellular proliferation and inflammation in DD is $\delta$-interferon. ${ }^{50}$ Molecular studies on cells derived from DD patients show that $\delta$-interferon can reduce cell proliferation, collagen production, and the expression of $\alpha$-smooth muscle actin, a predominant isoform of actin found in contractile cells called myofibroblasts. ${ }^{51,52}$ While there have been a number of studies showing the potential benefits of $\delta$-interferon in the treatment of DD, most of these studies have been conducted in vitro and whether these translates into clinical improvements is largely unknown. One small pilot study reported a decrease in the size of the lesion(s) associated with DD and that, at least in hypertrophic scar tissue, treatment with $\delta$-interferon resulted in a decrease of $\alpha$-smooth muscle actin expression and myofibroblast formation by immunohistochemistry. ${ }^{50}$ This study was not specific to DD, and included only four patients with DD in the hand, while the remainder presented with hypertrophic scars or plantar fibromatosis. Larger studies are required to determine whether the therapeutic benefits of $\delta$-interferon in cell cultures in laboratories can translate into improvements in hand function in the clinical setting.

DD has been viewed as an exaggerated wound healing response $^{53}$ and, since the wound healing response includes Type I and Type III collagen deposition, knowledge from this process has been applied to the study of DD. In this light, other biologic agents that may offer therapeutic benefits in DD, including agents that may affect the ratio between a group of specific collagenases found in wound healing, ie, matrix metalloproteinases (MMPs) and their inhibitors (tissue inhibitors of metalloproteinases, TIMPs). MMPs and their inhibitors regulate extracellular matrix (ECM) turnover and function. Studies have found correlations between MMP expression and DD progression and recurrence, ${ }^{54}$ and the MMP:TIMP ratio in DD fascia has been found to be abnormal. ${ }^{55}$ Treatment of cancer patients with a synthetic TIMP has been shown to result in DD, ${ }^{56}$ but other studies have shown that the use of ilomastat, a broad MMP inhibitor, leads to decreased mechanical tension generated by disease nodule and cord cells. ${ }^{57}$ The proposed pharmacologic manipulation of the MMP:TIMP ratio and how this affects DD $^{5,57-59}$ will require further study to determine the clinical applicability and potential effectiveness of such treatments on improving hand and joint function.

\section{Recent molecular studies}

There is a general consensus that a greater understanding of the molecular mechanism of DD will lead to the creation of more specific and effective treatment alternatives. The study of the cellular behavior of cells in diseased fascia, however, is hampered by the fact that the treatment of choice in the early stages of DD is observation. The genetic and molecular study of early-stage DD cells is thus not always feasible. The main tool to discern cellular abnormalities has been to evaluate the abnormal biologic behavior of DD cells obtained from surgical resection and to compare this with cells obtained from 
phenotypically normal palmar fascia or cells obtained from carpal tunnel release patients. This type of study using differential gene expression analysis, combined with molecular and functional studies of disease tissues and cells, has helped identify a number of putative abnormal mediators in DD. Several dysregulated genes in DD encode secreted ECM proteins, ${ }^{60-64}$ and these may play a role in disease progression or recurrence. While structural components of the ECM, such as collagens, laminin, fibronectin, and elastin are altered in $\mathrm{DD},{ }^{65,66}$ recent work has also identified proteases, including A Disintegrin and Metalloprotease (ADAM)-12, proteoglycans (notably PRG4), and "matricellular" components, including tenascin C and periostin, as well as specific members of the MMP family (MMP-2 and MMP-9) mentioned earlier, as being abnormally regulated. ${ }^{61,62,64} \mathrm{We}$ and others have demonstrated that periostin is abundant in the ECM of DD nodules and cords ${ }^{60,61,64,67}$ and we have also shown that periostin induces the proliferation and apoptosis of phenotypically normal fibroblasts derived from the palmar fascia adjacent to the DD cord, and myofibroblast differentiation of DD cells. ${ }^{64}$ ECM molecules, such as periostin, which initiate a differential response in DD cells and adjacent fibroblasts, may have different roles in DD progression and recurrence. The functional characterization of these ECM proteins, therefore, may identify novel therapeutic targets to prevent DD recurrence. ${ }^{68,69}$
Along these lines, our laboratory has chosen to focus on dysregulation of the Wnt- $\beta$-catenin pathway, because we first identified elevated total and tyrosine-phosphorylated $\beta$-catenin levels in DD. ${ }^{70}$ In our studies, we also found that the ECM plays a role in expression of the disease phenotype. ${ }^{65,66}$ The current hypothesis that we are working on is that DD cells modify their extracellular environment by secreting (or depleting) molecules that promote (or inhibit) myofibroblast differentiation in their collagenous ECM. Perhaps, when this modified ECM is left behind after surgical resection of the DD cord, there is the potential for these secreted factors to activate fibroblasts resident in the adjacent fascia to differentiate into myofibroblasts and promote disease recurrence. ${ }^{71}$ Currently, we are testing potential mediators of myofibroblast development by incorporating them into collagen substrates to mimic the in vivo environment and, in this way, we have demonstrated that a collagen-enriched substrate modifies transforming growth factor-beta (TGF- $\beta$ ) signaling in DD cells. ${ }^{72}$ We have also demonstrated that periostin, a TGF- $\beta$-induced and abundant component of the DD ECM, promotes myofibroblast differentiation of primary DD cells and have uncovered evidence of insulin-like growth factor (IGF) and IGF binding protein (IGFBP) changes in DD (see Figure 1). The latter interactions are intriguing from several perspectives. Firstly, ADAM-12, which is abundant in the

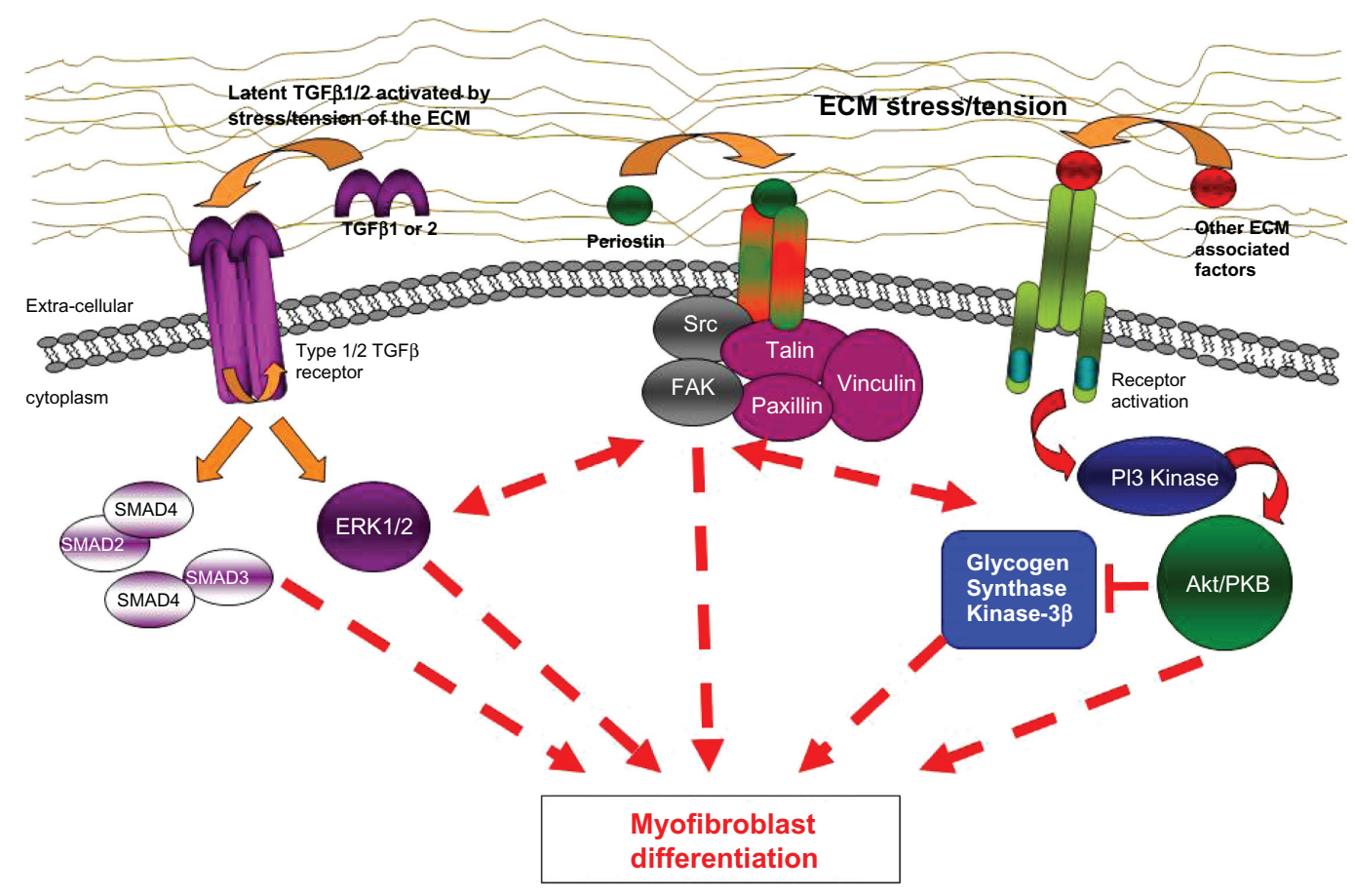

Figure I Proposed scheme in which TGF- $\beta$ signalling, ECM stress tension, and/or other ECM-associated factors may lead to dysregulation of myofibroblast differentiation. These pathways seem to be involved in the molecular pathogenesis of Dupuytren's disease and targeted interruption of abnormal signalling components may lead to future treatment approaches.

Abbreviations: ECM, extracellular matrix;TGF- $\beta$, transforming growth factor-beta. 
DD tissue, has been shown to cleave a subset of IGFBPs and release IGFs to stimulate cell growth and proliferation ${ }^{73,74}$. In parallel, another IGFBP that is not a target of ADAM-12, IGFBP-6, has been shown to be specifically and potently downregulated in desmoid tumors ${ }^{75}$ and DD (our unpublished data) by TGF- $\beta$ signaling. Finally, IGF and IGFBP levels are consistently dysregulated in diabetes, ${ }^{76-79}$ a metabolic condition frequently linked to DD predisposition. ${ }^{6,80,81}$ How all these findings will translate into clinical treatment is as yet unclear, but delineation of the abnormal molecular pathophysiology of DD is necessary to design rational molecular treatment methods. Moreover, while DD is a difficult clinical problem in its own right, DD is associated with other fibroproliferative diseases, including Peyronie's disease, ${ }^{60,82}$ Lederhose disease,${ }^{83,84}$ frozen shoulder syndrome (adhesive capsulitis), ${ }^{85-87}$ and desmoid tumor (aggressive polyfibromatosis). ${ }^{8}$ Research into the molecular pathogenesis of these diseases has shown that many of these disorders are characterized by dysregulated cellular proliferation and myofibroblast differentiation. Therefore, identification of molecules that induce myofibroblast development in DD may have broad consequences for the treatment of these other diseases and further research into the molecular pathogenesis of DD remains important.

\section{Disclosure}

The authors report no conflict of interest in this work.

\section{References}

1. Pratt AL, Byrne G. The lived experience of Dupuytren's disease of the hand. J Clin Nurs. 2009;18(12):1793-1802.

2. Rayan GM. Dupuytren disease: Anatomy, pathology, presentation, and treatment. J Bone Joint Surg Am. 2007;89(1):189-198.

3. Shaw RB Jr, Chong AK, Zhang A, Hentz VR, Chang J. Dupuytren's disease: history, diagnosis, and treatment. Plast Reconstr Surg. 2007;120(3):44e-54e.

4. McFarlane RM. Patterns of the diseased fascia in the fingers in Dupuytren's contracture. Displacement of the neurovascular bundle. Plast Reconstr Surg. 1974;54(1):31-44.

5. Watson HK, Paul H Jr. Pathologic anatomy. Hand Clin. 1991; 7(4):661-668.

6. Ross DC. Epidemiology of Dupuytren's disease. Hand Clin. 1999;15(1):53-62, vi.

7. Childs SG. Dupuytren's disease. Orthop Nurs. 2005;24(2):160-163; quiz 164-165.

8. McFarlane RM. On the origin and spread of Dupuytren's disease. J Hand Surg Am. 2002;27(3):385-390.

9. Egawa T, Senrui H, Horiki A, Egawa M. Epidemiologoy of the Oriental patient. Dupuytren's disease Biology and Treatment. Edinburgh, UK: Churchill Livingstone; 1990:239-245.

10. Gudmundsson KG, Arngrimsson R, Sigfusson N, Bjornsson A, Jonsson T. Epidemiology of Dupuytren's disease: clinical, serological, and social assessment. The Reykjavik Study. J Clin Epidemiol. 2000;53(3):291-296.

11. Hueston J. The Dupuytren's diathesis. In: Dupuytren's Contracture. Edinburgh, UK: Churchill Livingstone; 1963:51-63.
12. Hindocha S, Stanley JK, Watson S, Bayat A. Dupuytren's diathesis revisited: Evaluation of prognostic indicators for risk of disease recurrence. J Hand Surg [Am]. 2006;31(10):1626-1634.

13. Cagliero E, Apruzzese W, Perlmutter GS, Nathan DM. Musculoskeletal disorders of the hand and shoulder in patients with diabetes mellitus. Am J Med. 2002;112(6):487-490.

14. Arkkila PE, Koskinen PJ, Kantola IM, Ronnemaa T, Seppanen E, Viikari JS. Dupuytren's disease in type I diabetic subjects: investigation of biochemical markers of type III and I collagen. Clin Exp Rheumatol. 2000;18(2):215-219.

15. Arafa M, Noble J, Royle SG, Trail IA, Allen J. Dupuytren's and epilepsy revisited. J Hand Surg Br. 1992;17(2):221-224.

16. Burge P, Hoy G, Regan P, Milne R. Smoking, alcohol and the risk of Dupuytren's contracture. J Bone Joint Surg Br. 1997;79(2):206-210.

17. Godtfredsen NS, Lucht H, Prescott E, Sorensen TI, Gronbaek M. A prospective study linked both alcohol and tobacco to Dupuytren's disease. J Clin Epidemiol. 2004;57(8):858-863.

18. Gudmundsson KG, Arngrimsson R, Jonsson T. Dupuytren's disease, alcohol consumption and alcoholism. Scand J Prim Health Care. 2001;19(3):186-190.

19. Lucas G, Brichet A, Roquelaure Y, Leclerc A, Descatha A. Dupuytren's disease: personal factors and occupational exposure. Am J Ind Med. 2008;51(1):9-15.

20. Logan AJ, Mason G, Dias J, Makwana N. Can rock climbing lead to Dupuytren's disease? Br J Sports Med. 2005;39(9):639-644.

21. Thomas PR, Clarke D. Vibration white finger and Dupuytren's contracture: are they related? Occup Med (Lond). 1992;42(3):155-158.

22. Loos B, Puschkin V, Horch RE. 50 years experience with Dupuytren's contracture in the Erlangen University Hospital - a retrospective analysis of 2919 operated hands from 1956 to 2006. BMC Musculoskelet Disord. 2007;8:60.

23. Elliot D. The early history of Dupuytren's disease. Hand Clin. 1999;15(1):1-19, v.

24. Rayan GM. Nonoperative treatment of Dupuytren's disease. J Hand Surg Am. 2008;33(7):1208-1210.

25. Hueston JT. The table top test. Hand. 1982;14(1):100-103.

26. Ross DC, Gan BS. Acquired diseases of the hand. In: Siemionow M, editor. Textbook of Plastic Surgery. New York, NY: Springer; 2010: 583-597.

27. Swartz WM, Lalonde DH. MOC-PS(SM) CME article: Dupuytren's disease. Plast Reconstr Surg. 2008;121(Suppl 4):1-10.

28. McIndoe A, Beare RL. The surgical management of Dupuytren's contracture. Am J Surg. 1958;95(2):197-203.

29. Rowley DI, Couch M, Chesney RB, Norris SH. Assessment of percutaneous fasciotomy in the management of Dupuytren's contracture. $J$ Hand Surg Br. 1984;9(2):163-164.

30. van Rijssen AL, Werker PM. Percutaneous needle fasciotomy in dupuytren's disease. J Hand Surg Br. 2006;31(5):498-501.

31. Cheng HS, Hung LK, Tse WL, Ho PC. Needle aponeurotomy for Dupuytren's contracture. J Orthop Surg (Hong Kong). 2008; 16(1):88-90.

32. Foucher G, Medina J, Navarro R. Percutaneous needle aponeurotomy: complications and results. J Hand Surg. 2003;28(5): $427-431$.

33. Brotherston TM, Balakrishnan C, Milner RH, Brown HG. Long term follow-up of dermofasciectomy for Dupuytren's contracture. Br J Plast Surg. 1994;47(6):440-443.

34. Armstrong JR, Hurren JS, Logan AM. Dermofasciectomy in the management of Dupuytren's disease. J Bone Joint Surg Br. 2000; 82(1):90-94.

35. Larson D, Jerosch-Herold C. Clinical effectiveness of post-operative splinting after surgical release of Dupuytren's contracture: a systematic review. BMC Musculoskelet Disord. 2008;9:104.

36. Evans RB, Dell PC, Fiolkowski P. A clinical report of the effect of mechanical stress on functional results after fasciectomy for Dupuytren's contracture. J Hand Ther. 2002;15(4):331-339. 
37. McFarlane RM, McGrouther DA. Complications and their management. In: McFarlane RM, Flint DA, editors. Dupuytren's Disease. Edinburgh, UK: Churchill Livingstone; 1990:348-364.

38. Hueston JT. Enzymic fasciotomy. Hand. 1971;3(1):38-40.

39. Bailey AJ, Sims TJ, Gabbiani G, Bazin S, LeLous M. Collagen of Dupuytren's disease. Clin Sci Mol Med. 1977;53(5):499-502.

40. Brickley-Parsons D, Glimcher MJ, Smith RJ, Albin R, Adams JP. Biochemical changes in the collagen of the palmar fascia in patients with Dupuytren's disease. J Bone Joint Surg Am. 1981;63(5):787-797.

41. Hurst LC, Badalamente MA, Hentz VR, et al. Injectable collagenase clostridium histolyticum for Dupuytren's contracture. $N$ Engl J Med. 2009;361(10):968-979.

42. Badalamente MA, Hurst LC, Hentz VR. Collagen as a clinical target: nonoperative treatment of Dupuytren's disease. J Hand Surg Am. 2002;27(5):788-798.

43. Badalamente MA, Hurst LC. Efficacy and safety of injectable mixed collagenase subtypes in the treatment of Dupuytren's contracture. J Hand Surg Am. 2007;32(6):767-774.

44. Watt AJ, Curtin CM, Hentz VR. Collagenase injection as nonsurgical treatment of dupuytren's disease: 8-year follow-up. J Hand Surg Am. 2010;35(4):534-539, 539 e531.

45. Ketchum LD, Donahue TK. The injection of nodules of Dupuytren's disease with triamcinolone acetonide. J Hand Surg Am. 2000; 25(6):1157-1162.

46. Pagnotta A, Specchia N, Soccetti A, Manzotti S, Greco F. Responsiveness of Dupuytren's disease fibroblasts to 5 alpha-dihydrotestosterone. J Hand Surg Am. 2003;28(6):1029-1034.

47. Meek RM, McLellan S, Reilly J, Crossan JF. The effect of steroids on Dupuytren's disease: role of programmed cell death. J Hand Surg Br. 2002;27(3):270-273.

48. Newman RJ. Local skin depigmentation due to corticosteroid injection. Br Med J (Clin Res Ed). 1984;288(6432):1725-1726.

49. Oikarinen A, Autio P. New aspects of the mechanism of corticosteroid-induced dermal atrophy. Clin Exp Dermatol. 1991;16(6): 416-419.

50. Pittet B, Rubbia-Brandt L, Desmouliere A, et al. Effect of gammainterferon on the clinical and biologic evolution of hypertrophic scars and Dupuytren's disease: an open pilot study. Plast Reconstr Surg 1994;93(6):1224-1235.

51. Sanders JL, Dodd C, Ghahary A, Scott PG, Tredget EE. The effect of interferon-alpha2b on an in vitro model Dupuytren's contracture. J Hand Surg Am. 1999;24(3):578-585

52. Tanaka K, Sano K, Nakano T, Yuba K, Kinoshita M. Suppression of alpha smooth muscle actin expression by IFN-gamma in established myofibroblast cell lines. J Interferon Cytokine Res. 2007;27(10):835-839.

53. Bowley E, O'Gorman DB, Gan BS. Beta-catenin signaling in fibroproliferative disease. J Surg Res. 2007;138(1):141-150.

54. Johnston P, Larson D, Clark IM, Chojnowski AJ. Metalloproteinase gene expression correlates with clinical outcome in Dupuytren's disease. J Hand Surg Am. 2008;33(7):1160-1167.

55. Ulrich D, Hrynyschyn K, Pallua N. Matrix metalloproteinases and tissue inhibitors of metalloproteinases in sera and tissue of patients with Dupuytren's disease. Plast Reconstr Surg. 2003;112(5): 1279-1286.

56. Hutchinson JW, Tierney GM, Parsons SL, Davis TR. Dupuytren's disease and frozen shoulder induced by treatment with a matrix metalloproteinase inhibitor. J Bone Joint Surg Br. 1998;80(5):907-908.

57. Townley WA, Cambrey AD, Khaw PT, Grobbelaar AO. The role of an MMP inhibitor in the regulation of mechanical tension by Dupuytren's disease fibroblasts. J Hand Surg Eur Vol. 2009;34(6):783-787.

58. Townley WA, Cambrey AD, Khaw PT, Grobbelaar AO. Matrix metalloproteinase inhibition reduces contraction by dupuytren fibroblasts. J Hand Surg Am. 2008;33(9):1608-1616.

59. Pasternak B, Aspenberg P. Metalloproteinases and their inhibitorsdiagnostic and therapeutic opportunities in orthopedics. Acta Orthop. 2009;80(6):693-703.
60. Qian A, Meals RA, Rajfer J, Gonzalez-Cadavid NF. Comparison of gene expression profiles between Peyronie's disease and Dupuytren's contracture. Urology. 2004;64(2):399-404.

61. Rehman S, Salway F, Stanley JK, Ollier WE, Day P, Bayat A. Molecular phenotypic descriptors of Dupuytren's disease defined using informatics analysis of the transcriptome. J Hand Surg Am. 2008;33(3): 359-372.

62. Shih B, Brown JJ, Armstrong DJ, Lindau T, Bayat A. Differential Gene expression analysis of subcutaneous fat, fascia, and Skin overlying a Dupuytren's disease Nodule in comparison to control tissue. Hand (NY). 2009;4(3):294-301.

63. Satish L, Laframboise WA, O'Gorman DB, et al. Identification of differentially expressed genes in fibroblasts derived from patients with Dupuytren's Contracture. BMC Med Genomics. 2008;1:10.

64. Vi L, Feng L, Zhu RD, et al. Periostin differentially induces proliferation, contraction and apoptosis of primary Dupuytren's disease and adjacent palmar fascia cells. Exp Cell Res. 2009;315(20): 3574-3586.

65. Howard JC, Varallo VM, Ross DC, et al. Elevated levels of beta-catenin and fibronectin in three-dimensional collagen cultures of Dupuytren's disease cells are regulated by tension in vitro. BMC Musculoskelet Disord. 2003;4:16

66. Howard JC, Varallo VM, Ross DC, et al. Wound healing-associated proteins Hsp47 and fibronectin are elevated in Dupuytren's contracture. J Surg Res. 2004;117(2):232-238.

67. Shih B, Wijeratne D, Armstrong DJ, Lindau T, Day P, Bayat A. Identification of biomarkers in Dupuytren's disease by comparative analysis of fibroblasts versus tissue biopsies in disease-specific phenotypes. J Hand Surg Am. 2009;34(1):124-136.

68. Sedic M, Jurisic D, Stanec Z, Hock K, Pavelic K, Kraljevic Pavelic S. Functional genomics in identification of drug targets in Dupuytren's contracture. Front Biosci. 2010;15:57-64.

69. Kraljevic Pavelic S, Sedic M, Hock K, et al. An integrated proteomics approach for studying the molecular pathogenesis of Dupuytren's disease. J Pathol. 2009;217(4):524-533.

70. Varallo VM, Gan BS, Seney S, et al. Beta-catenin expression in Dupuytren's disease: potential role for cell-matrix interactions in modulating beta-catenin levels in vivo and in vitro. Oncogene. 2003;22(24):3680-3684.

71. Vi L, Gan BS, O'Gorman DB. The potential roles of cell migration and extra-cellular matrix interactions in Dupuytren's disease progression and recurrence. Med Hypotheses. 2010;74(3):510-512.

72. Vi L, Njarlangattil A, Wu Y, Gan BS, O’Gorman DB. Type-1 Collagen differentially alters beta-catenin accumulation in primary Dupuytren's Disease cord and adjacent palmar fascia cells. BMC Musculoskelet Disord. 2009;10:72.

73. Loechel F, Fox JW, Murphy G, Albrechtsen R, Wewer UM. ADAM 12-S cleaves IGFBP-3 and IGFBP-5 and is inhibited by TIMP-3. Biochem Biophys Res Commun. 2000;278(3):511-515.

74. Shi Z, Xu W, Loechel F, Wewer UM, Murphy LJ. ADAM 12, a disintegrin metalloprotease, interacts with insulin-like growth factor-binding protein-3. J Biol Chem. 2000;275(24):18574-18580.

75. Denys H, Jadidizadeh A, Amini Nik S, et al. Identification of IGFBP-6 as a significantly downregulated gene by beta-catenin in desmoid tumors. Oncogene. 2004;23(3):654-664

76. Chen X, Ferry RJ Jr. Novel actions of IGFBP-3 on intracellular signaling pathways of insulin-secreting cells. Growth Horm IGF Res. 2006;16(1):41-48.

77. Cusi K, DeFronzo R. Recombinant human insulin-like growth factor I treatment for 1 week improves metabolic control in type 2 diabetes by ameliorating hepatic and muscle insulin resistance. J Clin Endocrinol Metab. 2000;85(9):3077-3084.

78. Lopez-Bermejo A, Khosravi J, Fernandez-Real JM, et al. Insulin resistance is associated with increased serum concentration of IGFbinding protein-related protein 1 (IGFBP-rP1/MAC25). Diabetes. 2006;55(8):2333-2339. 
79. Mohamed-Ali V, Pinkney J. Therapeutic potential of insulin-like growth factor-1 in patients with diabetes mellitus. Treat Endocrinol. 2002;1(6): 399-410.

80. Hart MG, Hooper G. Clinical associations of Dupuytren's disease. Postgrad Med J. 2005;81(957):425-428.

81. Arkkila PE, Kantola IM, Viikari JS. Dupuytren's disease: association with chronic diabetic complications. J Rheumatol. 1997;24(1): 153-159.

82. Carrieri MP, Serraino D, Palmiotto F, Nucci G, Sasso F. A case-control study on risk factors for Peyronie's disease. J Clin Epidemiol. 1998; 51(6):511-515.

83. Classen DA, Hurst LN. Plantar fibromatosis and bilateral flexion contractures: a review of the literature. Ann Plast Surg. 1992;28(5):475-478.
84. Donato RR, Morrison WA. Dupuytren's disease in the feet causing flexion contractures in the toes. J Hand Surg. 1996;21(3):364-366.

85. Smith SP, Devaraj vs Bunker TD. The association between frozen shoulder and Dupuytren's disease. J Shoulder Elbow Surg. 2001;10(2): 149-151.

86. Bunker TD, Anthony PP. The pathology of frozen shoulder. A Dupuytren-like disease. J Bone Joint Surg Br. 1995;77(5):677-683.

87. Bunker TD, Reilly J, Baird KS, Hamblen DL. Expression of growth factors, cytokines and matrix metalloproteinases in frozen shoulder. J Bone Joint Surg Br. 2000;82(5):768-773.

88. Lee YC, Chan HH, Black MM. Aggressive polyfibromatosis: a 10 year follow-up. Australas J Dermatol. 1996;37(4):205-207.

\section{Publish your work in this journal}

Therapeutics and Clinical Risk Management is an international, peerreviewed journal of clinical therapeutics and risk management, focusing on concise rapid reporting of clinical studies in all therapeutic areas, outcomes, safety, and programs for the effective, safe, and sustained use of medicines. This journal is indexed on PubMed Central, CAS,
EMBase, Scopus and the Elsevier Bibliographic databases. The manuscript management system is completely online and includes a very quick and fair peer-review system, which is all easy to use. Visit http://www.dovepress.com/testimonials.php to read real quotes from published authors.

Submit your manuscript here: http://www.dovepress.com/therapeutics-and-clinical-risk-management-journal 